\title{
Nutritional Status of Patients with Hepatobiliary-Pancreatic Surgical Disease
}

\author{
Sang Soo Eom, M.D., B.S. ${ }^{1 * *}$, Yong Chan Shin, M.D., M.S. ${ }^{1, *}$, Chang-Sup Lim, M.D., Ph.D. ${ }^{2}$ In Woong Han, M.D., Ph.D. ${ }^{3}$, \\ Woohyun Jung, M.D., Ph.D. ${ }^{4}$ Yoonhyeong Byun, M.D., B.S. ${ }^{5}$, Dong Wook Choi, M.D., Ph.D. ${ }^{3}$, Jin Seok Heo, M.D., Ph.D. , \\ Hongbeom Kim, M.D., M.S. ${ }^{5}$
}

${ }^{1}$ Department of Surgery, Ilsan Paik Hospital, Inje University College of Medicine, Goyang, ${ }^{2}$ Department of Surgery, Seoul Metropolitan Government - Seoul National University Boramae Medical Center, Seoul National University College of Medicine, Seoul, ${ }^{3}$ Department of Surgery, Samsung Medical Center, Sungkyunkwan University School of Medicine, Seoul, ${ }^{4}$ Department of Surgery, Ajou University School of Medicine, Suwon, ${ }^{5}$ Department of Surgery, Seoul National University Hospital, Seoul National University College of Medicine, Seoul, Korea

Purpose: This study examined the nutritional status of patients with hepatobiliary-pancreatic diseases before surgery to establish basic reference data.

Materials and Methods: This study evaluated retrospectively 2,322 patients admitted for hepatobiliary-pancreatic surgery between 2014 and 2016 at four Korean medical institutions using the body mass index (BMI) score. The prognostic nutrition index (PNI) was calculated in patients diagnosed with malignant diseases.

Results: The mean BMI was $24.0 \mathrm{~kg} / \mathrm{m}^{2}$ (range, $\left.13.2 \sim 39.1 \mathrm{~kg} / \mathrm{m}^{2}\right)$. The patients were classified as low BMI $(<21.5 \mathrm{~kg} /$ $\mathrm{m}^{2}$, below 25 percentile), intermediate BMI $\left(21.5 \sim 25.5 \mathrm{~kg} / \mathrm{m}^{2}\right)$, and high BMI $\left(>25.5 \mathrm{~kg} / \mathrm{m}^{2}\right.$, above 75 percentile). There were significant differences in the age, sex distribution, ASA classification, type of hospitalization, biliary drainage, organ, and pathology diagnosis between the pairs among the low, intermediate, and high BMI groups. Among the three BMI groups, the complication rate of the low BMI group was highest ( $34.4 \%$ vs. $29.7 \%$ vs. $25.8 \% \mathrm{P}=0.005)$. The median lengths of hospital stay in the low, intermediate, and high BMI groups were 9, 9, and 7 days, respectively $(\mathrm{P}<0.001)$. Multivariate analysis revealed the risk factors of the low BMI group to be a higher ASA classification, biliary drainage, pancreatic disease, and malignant disease. The group with $\mathrm{PNI}<45$ had significantly longer hospital stays than the group with $\mathrm{PNI} \geq 45(\mathrm{P}<0.001)$.

Conclusion: Patients with a low BMI had a higher ASA classification, preoperative biliary drainage, pancreatic disease, and malignant disease. The low PNI group had significantly longer hospital stays than the high PNI group. Screening of the preoperative nutritional status is necessary for assessing the risk of malnutrition and its treatment.

Keywords: Nutritional status, Body mass index, Serum albumin, Biliary tract disease, Pancreatic disease, Surgery

\section{INTRODUCTION}

Although there have been remarkable improvements in the operative and postoperative techniques for hepatobiliarypancreatic diseases, the morbidity and mortality rates after surgery have remained relatively high, compared to other or-

Received April 1, 2020; Revised June 17, 2020; Accepted July 1, 2020

Corresponding author: Hongbeom Kim

E-mail surgeonkhb@gmail.com (iD ORCID https://orcid.org/0000-0002-1595-0135

*Sang Soo Eom and Yong Chan Shin contributed equally to this work.

This study was supported by the 2017 Korean Society of Surgical Metabolism and Nutrition Research Grant.

(i) \& This is an Open Access article distributed under the terms of the Creative Commons Attribution Non-Commercial License (http://creativecommons.org/licenses/ by-nc/4.0), which permits unrestricted non-commercial use, distribution, and reproduction in any medium, provided the original work is properly cited. 
gan diseases. Notably, poor nutritional status is an important risk factor for perioperative morbidity and mortality. Recent results from La Torre et al. [1] indicated that patients who underwent pancreatic resection for malignant tumors are usually malnourished; additionally, malnutrition is a relevant predictor of postoperative morbidity and mortality after pancreatic surgery.

Therefore, a variety of anamnestic scores,[2,3] anthropometric studies,[4] biochemical serum markers,[5] and electrophysiologic studies [6] are currently used for nutritional status screening. The nutrition risk score (NRS) is a simple and safe tool that assesses the nutritional intake as well as the extent of stress associated with the underlying disease.[3] The nutrition risk index (NRI), which is based on the serum albumin concentration, has been shown to identify patients at risk for postoperative complications.[7,8] Schiesser et al. [9] reported that the NRS and NRI correlate with the incidence and severity of perioperative complications in gastrointestinal (GI) surgery. The prognostic nutrition index (PNI), which is based on the serum albumin concentration and lymphocyte count, reflects nutritional status and systemic inflammation. It also has been reported to be associated with prognosis in various diseases.[10-12]

The nutritional factors are affected by the eating habits, the geographical and eating factors should be considered. However, since there is no large-scale study on the nutritional status of patients who have undergone hepatobiliary-pancreatic surgery in Korea. This study was performed to investigate the preoperative nutritional status of patients with hepatobiliarypancreatic diseases and establish basic reference data.

\section{MATERIALS AND METHODS}

The medical records of 2,349 consecutive patients who underwent surgery for benign or malignant hepato-biliarypancreatic disease between 2014 and 2016 at 4 Korean medical institutions (Ilsan Paik hospital, Samsung medical center, Boramae hospital, and Dongguk university Ilsan hospital) were retrospectively reviewed.

The nutritional status was evaluated by preoperative serum albumin and body mass index (BMI), which are key parameters of the NRS or NRI. Height and weight were used to determine the $\mathrm{BMI}\left[\mathrm{BMI}=\right.$ weight $(\mathrm{kg}) /$ height $\left.(\mathrm{m})^{2}\right]$. First, the patients were classified as low BMI (below 25 percentile), intermediate BMI (between 25 percentile and 75 percentile), and high BMI (above 75 percentile). In addition, we classified the patients into patients with BMI lower than 25\% and others to evaluate risk factors for low BMI.

As an assessment of systemic inflammatory response, the prognostic nutrition index (PNI) was calculated as serum albumin $(\mathrm{g} / \mathrm{L})+0.005 \times$ number of lymphocytes per $\mu \mathrm{l}$ in patients diagnosed with malignant disease with preoperative serum lymphocyte record.[10-12]

Continuous variables are presented as mean (range), un- less stated otherwise. Nominal data were compared using $\chi^{2}$ tests or Fisher's exact tests and continuous variables using Student t-tests, Mann-Whitney $U$ tests or Kruskal-Wallis test. Factors with $\mathrm{P}<0.100$ in univariate analysis were included in multivariable analysis. Statistical analysis was performed using SPSS, version 21.0 (IBM, Armonk, New York, USA) with Pvalues less than 0.05 considered statistically significant. This study was approved by the institutional review board of each participating center (DUIH: 2018-01-044, BMC: 2018-42051, SMC: 2017-07-016-005 and IPH: 2017-12-008).

\section{RESULTS}

\section{Patient characteristics}

A total of 2,349 patients were enrolled in this study; however, some patients were excluded from the study due to incomplete pathologic reports or inaccurate naming of the operations. Therefore, the study evaluated a total of 2,322 patients. The clinical characteristics of the patients are shown in Table 1. This study included 1,354 (58.3\%) males and $968(41.7 \%)$ females with a mean age of 62.4 years (range, 19 97 years). Overall, 1,496 patients (64.4\%) were admitted in the hospital by outpatient clinic and the other 826 patients (35.6\%) patients were admitted through the emergency room (ER). Most of the patients (1,528 patients [65.8\%]) were classified as 2 by the American Society of Anesthesiologists (ASA) classi-fication. The distribution of diagnosis was 1,617 patients $(69.6 \%)$ with hepatobiliary diseases and 705 patients $(30.4 \%)$ with pancreatic diseases. There were 824 patients (35.5\%) who underwent preoperative biliary drainage. Additionally, 1,123 patients (48.4\%) were pathologically diagnosed with malignant diseases. The majority of the study patients underwent cholecystectomy (897 patients, 38.6\%) followed by pancreatoduodenectomy (569 patients, $24.5 \%$ ) and distal pancreatectomy (280 patients, 12.1\%).

The mean height was $1.62 \mathrm{~m}$ (range, 1.23 1.88 m), the mean body weight was $63.4 \mathrm{~kg}$ (range, 30.9 123 kg), and the mean BMI was $24.0 \mathrm{~kg} / \mathrm{m}^{2}$ (range, $13.2 \sim 39.1 \mathrm{~kg} / \mathrm{m}^{2}$ ). The mean serum albumin concentration was $4.1 \mathrm{~g} / \mathrm{dl}$ (range, 2 6.6 $\mathrm{g} / \mathrm{dl}$ ). According to classification of obesity by BMI in the Korean Society for Metabolic and Bariatric Surgery, 105 patients $(4.5 \%)$ were underweight $\left(\mathrm{BMI}<18.5 \mathrm{~kg} / \mathrm{m}^{2}\right), 835(40.0 \%)$ were normal range overweight (BMI; $18.5 \mathrm{~kg} / \mathrm{m}^{2} \sim 22.9 \mathrm{~kg} / \mathrm{m}^{2}$ ), 545 (23.5\%) were pre-obese (BMI; $23.0 \mathrm{~kg} / \mathrm{m}^{2} \sim 24.9 \mathrm{~kg} / \mathrm{m}^{2}$ ), and $837(36.0 \%)$ were obese $\left(\mathrm{BMI} \geq 25.0 \mathrm{~kg} / \mathrm{m}^{2}\right)$.

\section{Clinical characteristics of patients according to the BMI group}

The patients were classified as low BMI $\left(<21.5 \mathrm{~kg} / \mathrm{m}^{2}\right.$, below 25 percentile), intermediate BMI $\left(21.5 \sim 25.5 \mathrm{~kg} / \mathrm{m}^{2}\right)$, and high BMI (>25.5 kg/m², above 75 percentile). The number of patients in low, intermediated and high BMI group were 517, 1104 and 701, respectively. There were significant differences in the age, sex distribution, ASA classification, 
Table 1. Clinical characteristics of patients

\begin{tabular}{|c|c|c|c|}
\hline Parameter & & Mean or Number & Range or \% \\
\hline \multirow[t]{2}{*}{ Sex } & Male & 1,354 & $58.3 \%$ \\
\hline & Female & 968 & $41.7 \%$ \\
\hline \multirow[t]{2}{*}{ Age (years) } & $<65$ & 1,282 & $55.2 \%$ \\
\hline & $\geq 65$ & 1,040 & $44.8 \%$ \\
\hline Height (m) & & 1.62 & $1.23 \sim 1.88$ \\
\hline Body Weight (kg) & & 63.4 & $30.9 \sim 123$ \\
\hline $\mathrm{BMI}^{*}\left(\mathrm{~kg} / \mathrm{m}^{2}\right)$ & & 24.0 & $13.2 \sim 39.1$ \\
\hline \multirow[t]{2}{*}{ Hospitalization } & Outpatient & 1,496 & $64.4 \%$ \\
\hline & $\mathrm{ER}^{\dagger}$ & 826 & $35.6 \%$ \\
\hline \multirow[t]{4}{*}{ Laboratory findings } & $\mathrm{WBC}^{\ddagger}$ & 8.33 & $1.68 \sim 30.5$ \\
\hline & $\mathrm{Hb}^{\S}$ & 13.2 & $6 \sim 19.2$ \\
\hline & PLT $^{\|}$ & 242 & $20 \sim 886$ \\
\hline & Albumin & 4.1 & $2 \sim 6.6$ \\
\hline \multirow[t]{4}{*}{$\mathrm{ASA}^{\varsigma}$ classification } & 1 & 578 & $24.9 \%$ \\
\hline & 2 & 1,528 & $65.8 \%$ \\
\hline & 3 & 210 & $9 \%$ \\
\hline & 4 & 6 & $0.3 \%$ \\
\hline \multirow[t]{2}{*}{ Disease } & Hepatobiliary & 1,617 & $69.6 \%$ \\
\hline & Pancreatic & 705 & $30.4 \%$ \\
\hline \multirow[t]{2}{*}{ Biliary drainage } & No & 1,498 & $64.5 \%$ \\
\hline & Yes & 824 & $35.5 \%$ \\
\hline \multirow[t]{2}{*}{ Pathology } & Benign & 1,199 & $51.6 \%$ \\
\hline & Malignancy & 1,123 & $48.4 \%$ \\
\hline \multirow[t]{7}{*}{ Operation type } & Pancreaticoduodenectomy & 569 & $24.5 \%$ \\
\hline & Distal pancreatectomy & 280 & $12.1 \%$ \\
\hline & Hemihepatectomy & 206 & $8.9 \%$ \\
\hline & Extended cholecystectomy & 138 & $5.9 \%$ \\
\hline & Bile duct segmental resection & 87 & $3.7 \%$ \\
\hline & Others** & 145 & $6.2 \%$ \\
\hline & Cholecystectomy & 897 & $38.6 \%$ \\
\hline
\end{tabular}

${ }^{*} \mathrm{BMI}=$ body mass index; ${ }^{\dagger} \mathrm{ER}=$ emergency room; ${ }^{\dagger} \mathrm{WBC}=$ white blood cell count; ${ }^{\S} \mathrm{Hb}=$ hemoglobin level; ${ }^{\|} \mathrm{PLT}=$ platelet count; 'ASA = American Society of anesthesiologist; ** Others operations were segmentectomy, open biopsy, bypass surgery, total pancreatectomy, enucleation, central pancreatectomy, hepato-pancreaticoduodenectomy, liver cyst unroofing, pseudocyst excision.

type of hospitalization, biliary drainage, organ and pathologic diagnosis between the pairs among low, intermediate, and high BMI groups. Among three BMI groups, the complication rate of low BMI group was highest $(34.4 \%$ vs $29.7 \%$ vs $25.8 \%$ $\mathrm{P}=0.005)$. The median length of hospital day were 9, 9 and 7 days in low, intermediate and high BMI group, respectively $(\mathrm{P}<0.001)$ (Table 2).

To identify clinical characteristics of low BMI group, univariate and multivariate analysis were performed between lower 25 percentile group and higher 75 percentile group. In the univariate analysis between patients with lower than $25 \% \mathrm{BMI}$ and others, higher ASA classification $(P=0.027)$, hospitalization through the outpatient clinic $(P=0.004)$, biliary drainage (external or internal, $P<0.001$ ), pancreatic disease $(P=0.005)$, malignant histology $(P<0.001)$, presence of complications $(\mathrm{P}=0.006$ and long hospital stay $(\mathrm{P}<0.001)$ were significantly associated with lower BMI scores (Table 3). Multivariate analysis of preoperative factors demonstrated that higher values of ASA classification, biliary drainage, pancreatic disease, and malignant disease were independent predictors of a low BMI. However there was no difference in length of hospital stay and complication rate between BMI groups. 
Table 2. Clinical characteristics of patients according to the $\mathrm{BMI}^{*}$ group

\begin{tabular}{|c|c|c|c|c|c|}
\hline & Total & $\begin{array}{c}\text { Low BMI* } \\
(n=517)\end{array}$ & $\begin{array}{c}\text { Intermediate BMI* } \\
(\mathrm{n}=1,104)\end{array}$ & $\begin{array}{c}\text { High BMI* } \\
(n=701)\end{array}$ & P-value \\
\hline Age (years) & & & & & 0.001 \\
\hline$<65$ & 1,282 & $281(54.4 \%)$ & $575(52.1 \%)$ & $426(60.8 \%)$ & \\
\hline$\geq 65$ & 1,040 & $236(45.6 \%)$ & $529(47.9 \%)$ & $275(39.2 \%)$ & \\
\hline Sex & & & & & 0.020 \\
\hline Male & 1,354 & $286(55.3 \%)$ & $677(62.3 \%)$ & $391(55.8 \%)$ & \\
\hline Female & 968 & $231(44.7 \%)$ & $427(38.7 \%)$ & $310(44.2 \%)$ & \\
\hline $\mathrm{ASA}^{\dagger}$ classification & & & & & 0.030 \\
\hline 1 & 578 & $116(22.4 \%)$ & $268(24.3 \%)$ & $194(37.7 \%)$ & \\
\hline 2 & 1,528 & $340(65.8 \%)$ & $750(67.9 \%)$ & $438(62.5 \%)$ & \\
\hline 3 & 210 & $58(11.2 \%)$ & $85(7.7 \%)$ & $67(9.6 \%)$ & \\
\hline 4 & 6 & $3(0.6 \%)$ & $1(0.1 \%)$ & $2(0.3 \%)$ & \\
\hline Hospitalization & & & & & $<0.001$ \\
\hline Outpatient & 1,496 & $361(69.8 \%)$ & $731(66.2 \%)$ & $404(57.6 \%)$ & \\
\hline $\mathrm{ER}^{\neq}$ & 826 & $156(30.2 \%)$ & $373(33.8 \%)$ & $297(42.4 \%)$ & \\
\hline Biliary drainage & & & & & $<0.001$ \\
\hline Yes & 825 & $219(42.3 \%)$ & $409(37.1 \%)$ & $197(28.1 \%)$ & \\
\hline No & 1,497 & $298(57.6 \%)$ & $695(62.9 \%)$ & $504(71.9 \%)$ & \\
\hline Disease & & & & & $<0.001$ \\
\hline Pancreas & 705 & $183(35.4 \%)$ & $355(32.2 \%)$ & $167(23.8 \%)$ & \\
\hline Biliary & 1,490 & $304(58.8 \%)$ & $690(62.5 \%)$ & $496(70.8 \%)$ & \\
\hline Liver & 127 & $30(5.8 \%)$ & $59(5.3 \%)$ & $38(5.4 \%)$ & \\
\hline Pathology & & & & & $<0.001$ \\
\hline Malignancy & 1,199 & $314(60.7 \%)$ & $585(52.9 \%)$ & $300(42.8 \%)$ & \\
\hline Benign & 1,123 & $203(39.2 \%)$ & $519(47.1 \%)$ & $401(57.2 \%)$ & \\
\hline Complication & & & & & 0.005 \\
\hline Yes & 687 & $178(34.4 \%)$ & $328(29.7 \%)$ & $181(25.8 \%)$ & \\
\hline No & 1,635 & $339(65.6 \%)$ & $776(70.3 \%)$ & $520(74.2 \%)$ & \\
\hline Hospital stay Median $\left(\mathrm{IQR}^{\S}\right)$ & $8(3 \sim 12)$ & $9(5 \sim 14)$ & $9(4 \sim 12)$ & $7(2 \sim 11)$ & $<0.001$ \\
\hline
\end{tabular}

${ }^{*} \mathrm{BMI}=$ body mass index; ${ }^{\dagger} \mathrm{ASA}=$ American Society of anesthesiologist; ${ }^{\dagger} \mathrm{ER}=$ emergency room, ${ }^{\S} \mathrm{IQR}=$ interquartile range.

\section{Prognostic nutrition index assessment}

PNI was calculated in 501 patients diagnosed with malignant diseases with preoperative serum lymphocyte record. The mean value of PNI was 50.08 (range, 23.53 73.43). Patients were divided into two groups based on the PNI distribution. The cut off values for dividing the two groups were set to 20 percentile, 30 percentile, and 40 percentile of the total distribution, and three analyzes were performed respectively. There was no difference between the rate of complications and PNI group. When the patient was divided into two groups based on the PNI value of 20 percentile, 45, the group with $\mathrm{PNI}<45$ had significantly longer hospital stays than the group with $\mathrm{PNI} \geq 45(\mathrm{P}<0.001)$ (Table 4).

\section{DISCUSSION}

Since the hepatobiliary-pancreatic surgery shows a high incidence of postoperative complications when compared to other surgeries, the nutritional status of the patients in this type of surgery has a significant effect on the postoperative prognosis. Additionally, as the nutritional factors are affected by the eating habits, the geographical and eating factors should be considered. However, since there is no large-scale study on the nutritional status of patients who have undergone hepatobiliary-pancreatic surgery in Korea, this study was performed for analyzing these data. The large-scale patient data were used to identify the nutritional status.

Although malnutrition is a well-recognized risk factor of postoperative complications in hepatobiliary-pancreatic surgery, its prevalence and severity is often underestimated. In 
Table 3. Correlation with $\mathrm{BMI}^{*}$ group and clinical characteristics of patients

\begin{tabular}{|c|c|c|c|c|c|c|c|}
\hline & \multirow[b]{2}{*}{ Total } & \multirow[b]{2}{*}{$\begin{array}{l}\text { Lower } 25 \% \text { BMI* }^{*} \\
\quad(n=517)\end{array}$} & \multirow[b]{2}{*}{$\begin{array}{l}\text { Higher } 75 \% \mathrm{BMI}^{*} \\
\quad(n=1,805)\end{array}$} & \multirow[b]{2}{*}{ P-value } & \multicolumn{3}{|c|}{ Multivariate analysis } \\
\hline & & & & & Odds ratio & $\begin{array}{c}95 \% \\
\text { Confidence } \\
\text { interval }\end{array}$ & P-value \\
\hline Age (years) & & & & 0.656 & & & \\
\hline$<65$ & 1,282 & $281(54.4 \%)$ & $1,001(55.5 \%)$ & & & & \\
\hline$\geq 65$ & 1,040 & $236(45.6 \%)$ & $804(45.5 \%)$ & & & & \\
\hline Sex & & & & 0.118 & & & \\
\hline Male & 1,354 & $286(55.3 \%)$ & $1,068(59.2 \%)$ & & & & \\
\hline Female & 968 & $231(44.7 \%)$ & $737(40.2 \%)$ & & & & \\
\hline $\mathrm{ASA}^{\dagger}$ classification & & & & 0.027 & 1.424 & $1.033 \sim 1.963$ & 0.031 \\
\hline 1 or 2 & 2,106 & $456(88.2 \%)$ & $1,650(91.4 \%)$ & & & & \\
\hline 3 or 4 & 216 & $61(11.8 \%)$ & $155(8.6 \%)$ & & & & \\
\hline Hospitalization & & & & 0.004 & 1.005 & $0.772 \sim 1.308$ & 0.972 \\
\hline Outpatient & 1,496 & $361(69.8 \%)$ & $1,135(62.9 \%)$ & & & & \\
\hline $\mathrm{ER}^{\dagger}$ & 826 & $156(30.2 \%)$ & $670(37.1 \%)$ & & & & \\
\hline Biliary drainage & & & & $<0.001$ & 1.344 & $1.081 \sim 1.671$ & 0.008 \\
\hline Yes & 824 & $219(42.4 \%)$ & $605(33.5 \%)$ & & & & \\
\hline No & 1,498 & $298(57.6 \%)$ & $1,200(66.5 \%)$ & & & & \\
\hline Disease & & & & 0.005 & 1.283 & $1.015 \sim 1.623$ & 0.037 \\
\hline Hepatobiliary & 1,617 & $334(64.6 \%)$ & $1,283(71.1 \%)$ & & & & \\
\hline Pancreas & 705 & $183(35.4 \%)$ & $522(28.9 \%)$ & & & & \\
\hline Pathology & & & & $<0.001$ & 1.381 & $1.067 \sim 1.788$ & 0.014 \\
\hline Benign & 1,123 & $203(39.2 \%)$ & $920(50.9 \%)$ & & & & \\
\hline Malignancy & 1,199 & $314(60.7 \%)$ & $885(49.0 \%)$ & & & & \\
\hline Complication & & & & 0.006 & 1.035 & $0.820 \sim 1.305$ & 0.775 \\
\hline Yes & 687 & $178(34.4 \%)$ & $509(28.2 \%)$ & & & & \\
\hline No & 1,635 & $339(65.6 \%)$ & $1296(71.8 \%)$ & & & & \\
\hline Hospital stay & & & & $<0.001$ & 1.136 & $0.881 \sim 1.465$ & 0.324 \\
\hline$\leq 8$ & 1,189 & $220(42.6 \%)$ & $969(81.5 \%)$ & & & & \\
\hline$>8$ & 1,133 & $297(57.4 \%)$ & $836(73.8 \%)$ & & & & \\
\hline
\end{tabular}

${ }^{*} \mathrm{BMI}=$ body mass index; ${ }^{\dagger} \mathrm{ASA}=$ American Society of anesthesiologist; ${ }^{*} \mathrm{ER}=$ emergency room.

Table 4. Prognostic nutrition index assessment

\begin{tabular}{lcccc}
\hline & & PNI $<45(\mathrm{n}=90)$ & PNI $\geq 45(\mathrm{n}=411)$ & P-value \\
\hline Complication* & & & & 0.281 \\
Yes & 247 & $49(54.5 \%)$ & $198(48.1 \%)$ & \\
No & 254 & $41(45.5 \%)$ & $213(51.9 \%)$ & $<0.001$ \\
Hospital stay (days) & $13(9 \sim 21)$ & $20(12 \sim 32)$ & $12(9 \sim 18)$ & \\
Median (IQR $\left.{ }^{\dagger}\right)$ & & & & \\
\hline
\end{tabular}

${ }^{*}$ Complication included cases higher than the Clavien-Dindo classification grade II. ${ }^{\dagger} \mathrm{IQR}=$ interquartile range.

a study to find a strong correlation between the nutritional risk screening scores NRS, NRI, and bioelectrical impedance analysis (BIA) and the incidence of postoperative morbidity using a validated classification system of surgical complications, the authors reported that the patients at nutritional risk experienced more severe complications compared with non-risk patients, which resulted in more reoperations and prolonged hospital stays.[9] PNI also useful nutritional scoring system, reflects nutritional status and systemic inflammation. It is based on the serum albumin concentration and lympho- 
cyte count, reflects nutritional status and systemic inflammation.[10-12] Okamura et al. [12] validate the power of various prognostic scores such as Glasgow Prognostic Score, neutrophil to lymphocyte ratio and PNI in hepatectomy patients. PNI was an independent predictor of overall survival (HR 2.01, $\mathrm{P}=0.007$ ).

Due to the increased risk of morbidity and mortality in malnourished surgical patients, the clinical and laboratory indicators of the nutritional status have been extensively investigated. Measuring preoperative albumin, weight loss, and BMI are the simplest methods used to evaluate and assess the malnutrition risk. Albumin level was a better predictor of some types of morbidity, particularly sepsis and major infections, than several other preoperative characteristics. [13] Hennessey et al. [14] showed that a preoperative serum albumin level $<30 \mathrm{mg} / \mathrm{dl}$ increased the risk of surgical site infection (SSI) 5.6-fold in their multivariate analysis of the relationship of serum albumin with SSI. La Torre et al. [1] reported that severe hypoalbuminemia was an independent predictor of the overall morbidity in patients undergoing resection for periampullary and pancreatic carcinoma.

In this study, it was observed that the prevalence of malnutrition was significantly greater in patients with higher ASA classification (3 or 4) or malignant diseases using the BMI score as variables for the evaluation of malnutrition. The reported rate of patients at nutritional risk is similar to our results in patients who underwent an operation for $\mathrm{Gl}$ cancer. $[9,15,16]$ Preoperative biliary drainage was also an independent predictor of mal-nutrition. Padillo et al. [17] showed that patients with obstructive jaundice due to benign or malignant tumors had lower concentrations of some of the visceral proteins before biliary drainage and concentrations of those proteins improved 10 days after biliary drainage. Exocrine pancreatic insufficiency caused by pancreatic disease affects the nutritional status of patients preoperatively. That would be a reason why the rate of patients with lower $25 \% \mathrm{BMI}$ in the pancreatic disease group was significantly higher than that in the hepatobiliary disease group.

The study has some limitations. First, this was a retrospective study. Thus, parameters such as weight loss, appetite, GI symptoms, which are necessary to calculate NRS and NRI could not be obtained. Evaluation of those scores would be helpful to assess the correlation among the different nutritional risk scores. Second, when the patients enrolled in this study were classified according to the definition of obesity by the Korean Society for Metabolic and Bariatric Surgery, the rate of the underweight group $(4.5 \%)$ was relatively low compared to other groups. Therefore, patients had to be divided into two groups (lower 25\% vs. higher 75\%) regardless of the normal range of $\mathrm{BMI}$ to determine the effectiveness of $\mathrm{BMI}$ as a factor related to nutritional status. And last, although $\mathrm{BMI}$ is one of the easiest indicators to assess nutritional status, BMI alone cannot be said to represent nutritional status. The individuals with low BMI are not always malnourished or undernourished, whereas individuals with a normal BMI can be malnourished. It is also likely that there is a wide variation in body composition and nutritional status in the overweight and obese populations. The purpose is to register a large number of patients, so the details are lacking.

In conclusion, higher values of ASA classification, biliary drainage, pancreatic disease, and malignant histology were correlated with low BMI. In low BMI group, the length of hospital day was longer and the complication rate was higher compared to high BMI group. Low PNI group had significantly longer hospital stays than high PNI group. Screening of preoperative nutritional status is necessary for the assessment of the risk of malnutrition and its treatment.

\section{CONFLICTS OF INTEREST}

The authors of this manuscript have no conflicts of interest to disclose.

\section{ORCID}

Sang Soo Eom, https://orcid.org/0000-0002-6252-7532

Yong Chan Shin, https://orcid.org/0000-0001-9808-1213

Chang-Sup Lim, https://orcid.org/0000-0002-2349-9647

In Woong Han, https://orcid.org/0000-0001-7093-2469

Woohyun Jung, https://orcid.org/0000-0003-1484-9024

Yoonhyeong Byun, https://orcid.org/0000-0002-4258-891X

Dong Wook Choi, https://orcid.org/0000-0002-5729-2273

Jin Seok Heo, https://orcid.org/0000-0001-6767-2790

Hongbeom Kim, https://orcid.org/0000-0002-1595-0135

\section{REFERENCES}

1. La Torre M, Ziparo V, Nigri G, Cavallini M, Balducci G, Ramacciato G. Malnutrition and pancreatic surgery: prevalence and outcomes. J Surg Oncol 2013;107:702-8.

2. Detsky AS, McLaughlin JR, Baker JP, Johnston N, Whittaker $\mathrm{S}$, Mendelson RA, et al. What is subjective global assessment of nutritional status? JPEN J Parenter Enteral Nutr 1987;11:8-13.

3. Reilly HM, Martineau JK, Moran A, Kennedy H. Nutritional screening--evaluation and implementation of a simple Nutrition Risk Score. Clin Nutr 1995;14:269-73.

4. Rodríguez G, Moreno LA, Blay MG, Blay VA, Fleta J, Sarría A, et al.; AVENA-Zaragoza Study Group. Body fat measurement in adolescents: comparison of skinfold thickness equations with dual-energy X-ray absorptiometry. Eur J Clin Nutr 2005;59:1158-66.

5. Reinhardt GF, Myscofski JW, Wilkens DB, Dobrin PB, Mangan JE Jr, Stannard RT. Incidence and mortality of hypoalbu-minemic patients in hospitalized veterans. JPEN J Parenter Enteral Nutr 1980;4:357-9.

6. Barbosa-Silva MC, Barros AJ. Bioelectric impedance and individual characteristics as prognostic factors for postoperative complications. Clin Nutr 2005;24:830-8.

7. Veterans Affairs Total Parenteral Nutrition Cooperative 
Study Group. Perioperative total parenteral nutrition in surgical patients. N Engl J Med 1991;325:525-32.

8. Buzby GP, Williford WO, Peterson OL, Crosby LO, Page $\mathrm{CP}$, Reinhardt GF, et al. A randomized clinical trial of total parenteral nutrition in malnourished surgical patients: the rationale and impact of previous clinical trials and pilot study on protocol design. Am J Clin Nutr 1988;47(2 Sup$\mathrm{pl}): 357-65$.

9. Schiesser M, Kirchhoff P, Müller MK, Schäfer M, Clavien PA. The correlation of nutrition risk index, nutrition risk score, and bioimpedance analysis with postoperative complications in patients undergoing gastrointestinal surgery. Surgery 2009;145:519-26.

10. Chan AW, Chan SL, Wong GL, Wong VW, Chong CC, Lai PB, et al. Prognostic Nutritional Index (PNI) predicts tumor recurrence of very early/early stage hepatocellular carcinoma after surgical resection. Ann Surg Oncol 2015;22:4138-48.

11. Goh BK, Chok AY, Allen JC Jr, Quek R, Teo MC, Chow PK, et al. Blood neutrophil-to-lymphocyte and platelet-tolymphocyte ratios are independent prognostic factors for surgically resected gastrointestinal stromal tumors. Surgery 2016;159:1146-56.
12. Okamura Y, Ashida R, Ito T, Sugiura T, Mori K, Uesaka K. Preoperative neutrophil to lymphocyte ratio and prognostic nutritional index predict overall survival after hepatectomy for hepatocellular carcinoma. World J Surg 2015;39:1501-9.

13. Gibbs J, Cull W, Henderson W, Daley J, Hur K, Khuri SF. Preoperative serum albumin level as a predictor of operative mortality and morbidity: results from the National VA Surgical Risk Study. Arch Surg 1999;134:36-42.

14. Hennessey DB, Burke JP, Ni-Dhonochu T, Shields C, Winter DC, Mealy K. Preoperative hypoalbuminemia is an independent risk factor for the development of surgical site infection following gastrointestinal surgery: a multiinstitutional study. Ann Surg 2010;252:325-9.

15. Pirlich M, Schütz T, Kemps M, Luhman N, Burmester GR, Baumann G, et al. Prevalence of malnutrition in hospitalized medical patients: impact of underlying disease. Dig Dis $2003 ; 21: 245-51$.

16. Bozzetti F. Nutrition and gastrointestinal cancer. Curr Opin Clin Nutr Metab Care 2001;4:541-6.

17. Padillo FJ, Rodriguez M, Gallardo JM, Andicoberry B, Naranjo A, Minõ $G$, et al. Changes in the pattern of visceral protein concentrations after internal biliary drainage in patients with obstructive jaundice. Eur J Surg 1999;165:550-5. 